Article

\title{
Towards improved Water-Energy-Climate Change nexus as- sessment in South Africa: A Participatory Approach
}

\author{
Steven Mathetsa ${ }^{1^{*}}$, Mulala Simatele ${ }^{2}$ and Isaac T Rampedi $^{3}$ \\ 1 Risk and Sustainability Division, Research Testing and Development, Eskom Holdings SOC, 5 Lower Germiston \\ Road, Rosherville, Cleveland, South Africa; steviemathetsa@gmail.com \\ 2 Global Change Institute, Department of Geography and Environmental Studies, University of the Witwatersrand, \\ Johannesburg, South Africa; Mulala.simatele.com \\ 3 Department of Geography, Environmental Management \& Energy Studies, University of Johannesburg, \\ Johannesburg, South Africa \\ * Correspondence: steviemathetsa@gmail.com; Tel.: (+27727204491)
}

\begin{abstract}
This paper discusses the use of a participatory approach to assess the level of understanding of the Water-Energy-Climate Change nexus in South Africa. The aim is to facilitate the development of well-coordinated, systematic, and holistic strategies for efficient management of the nexus and its implications in the country. The assessment was guided by the broader Integrated Water Resource Management framework, which promotes a participatory approach in the administration of water resources. The paper argues that despite the reasonable level of understanding of WECC, there is still a lack of integrated policy development and planning among key stakeholders. This is exacerbated by limited coordination and consultation among these stakeholders, particularly policymakers. This necessitates the urgent adoption of holistic and systems thinking approaches, and the promotion of collaboration among different stakeholders mandated to manage WECC sectors. Until such approaches are adopted, the WECC nexus will continue to impede the country's socioeconomic development and environmental wellbeing.
\end{abstract}

Keywords: participatory approach, WECC nexus, South Africa, integrated water resource management

\section{Introduction}

The acceleration of climate change and its impact on water and energy resources has heightened calls for a better understanding of the Water-Energy-Climate Change (WECC) nexus $[1,2,3]$. These calls are prompted mainly by the negative implications of the WECC nexus on attainment of the Sustainable Development Goals (SDGs). It is argued that the complex interplay between these three components necessitates a "nexus thinking" approach, and holistic, integrated, management of the WECC [4,5,3]. Evidence, however, indicates that the risks associated with this nexus have not been fully understood globally. A case in point is the current sectoral decision-making landscape, which signals limited understanding and acknowledgement of this nexus and its implications $[6,7,8,9]$. This continued fragmentation reveals a lack of urgency in migrating to integrated management of the nexus, particularly in poor and middle income countries. In Sub-Saharan Africa (SSA), the risks associated with WECC are estimated to be at an all-time high as the region faces the need to address the existing challenges of water scarcity, growing energy demand and lack of effective systems to deal with climate changes impacts [5,3]. The nexus has implications on the welfare of communities in SSA which comprise predominantly of poor and middle-class households. As such, it is imperative that the region fully embraces the "nexus thinking" approach if it is to promote the effective management of WECC.

As is the case globally, South Africa lacks integrated approaches for the management of different nexus configurations such as WECC [10,11,12]. This is as demonstrated by the 
preponderance of fragmented approaches in the planning and development of policies and strategies for addressing growing water, energy, and climate change challenges in the country $[13,3]$. This observation, coupled with a lack of urgency to implement mitigation measures as proposed by different scientists in the country, suggests that there is limited coordination and collaboration among key stakeholders such as researchers, policymakers and communities. There is, therefore, urgent need for the country to adopt contemporary approaches for analyzing the WECC nexus and for the promotion of "nexus thinking" in South Africa's policy development and planning landscape.

Cammerman (2009) [1] suggests managing the WECC nexus from a water-centric perspective. This approach is pertinent for countries such as South Africa, which face dire water status. Furthermore, Cammerman (2009) [1] and Head and Cammerman (2010) [2] are of the view that the Integrated Water Resources Management (IWRM) framework, a useful tool in facilitating sustainable water management, is effective for managing complex systems such as this nexus. Effective implementation of IWRM is dependent on four principles, one of which - a Participatory Approach (PA) - requires broad engagement of stakeholders, collaboration and informed decision-making within water resource management systems and related activities such as land use [14,15,9]. Drawing parallels between "nexus thinking" and PA, Hoolohan et al. (2018) [16] argued that engagement of multiple stakeholders is pivotal for bringing together actors from different spectra to promote holistic management of different nexus configurations such as WECC. Engaging key stakeholders has the potential to promote effective decision-making processes based on a common understanding of the complexity and challenges brought about by the nexus.

Given the implications of the WECC nexus on the achievement of South Africa's national developmental endevours, it is reasonable to suggest that comprehensive approaches such as stakeholder engagement be applied in assessing the understanding of the nexus, informing decision-making processes and for promoting collaborative efforts to manage this nexus. This paper, therefore, explores the extent to which the PA can be used as an analytical framework to assess understanding of WECC and improve the management of this nexus in South Africa. Different techniques are used to examine the stakeholders' perceptions of this nexus and gather suggestions on the development of resilient systems to manage the WECC. The paper provides a brief appraisal of developments relating to the PA as a vital tool in the management of complex systems such as water resources and nexus configurations. Of particular importance, the paper examines the importance of the PA in broadening the understanding of the WECC and proposals for the mitigation of the impacts of this nexus on all subsectors of the economy in South Africa.

\section{An appraisal of the emergence of the participatory approach as a decision-making tool}

The PA, which is also referred to as "stakeholder engagement" or "public participation" is not a new method in research or policy discussions. Studies focusing on the PA as a method for addressing complex societal development issues have, over the years, emphasized its importance as a tool for critical decision-making processes. Chambers (1994) [17] Babooa (2008) [18], Nyathi (2008) [19], and Legislative Sector Support [LLS] (2013) [20], for example, concur that the PA is an effective tool for ensuring the participation of various stakeholders in decision-making on issues concerning their welfare. The emphasis on this approach, particularly in democratic societies, is aimed at involving more local people in policy planning and implementation. Proponents argue that involvement of local stakeholders ensures greater utilisation of indigenous knowledge in the development of tools for managing emerging societal needs [21,22]. The strength of this approach lies in its potential for enabling communication and inclusive decision-making processes which consider the views of all affected stakeholders. Barreteau et al. (2013) [23] commend the PA for its capacity to stimulate social cohesion and enable decisions that are based on the realities of affected communities. In addition to promoting inclusive decision-making 
processes, Barbosa et al. (2017) [24] argued that the PA is a critical tool for ensuring strong and acceptable outcomes for adopted decisions.

Despite global agreement on the value of stakeholder engagement in facilitating socio-economic transformation and improved environmental wellbeing, top-down decision-making remains dominant in many societies, particularly in SSA [25]. In most cases, decisions are made by powerful and influential players prior to any consultation process or without meaningful consideration of the views of the people at the grassroots $[17,14]$. The partial or lack of comprehensive engagement with wider stakeholders often results in conflict or contradictions, particularly at the implementation stage of the decisions made. For instance, several local level decisions such as municipal demarcations often lead to conflicts in many regions. Nyathi (2008) [19] pointed out that, in South Africa, local communities believe the authorities does not carried out fully consultative and inclusive decision-making processes to ensure that community perspectives are considered. This highlight the importance of PA in decision-making processes associated with communities.

Denby et al. (2016) [26] argued that the development of resource-related projects or policies is often marked by a lack of comprehensive participation across SSA. Mathekga and Buccus (2006) [27], Prinsloo (2008) [28], and Fatch (2009) [29] have attributed this ineffective application of the PA to factors such as limited understanding of project contextualization and financial resource constraints within local and marginalized communities. These limitations have, however, not prevented countries such as South Africa from pursuing broad stakeholder participation within its critical systems such as policy development. An example of the endorsement of this approach is Section 195(1) (e) in the country's Constitution, which mandates public comment within the process of policy and strategy development $[30,19]$. This encourages the involvement of key stakeholders - including marginalised communities - in policymaking and implementation processes. Participations such as these allow communities to share their knowledge and experiences, and broadens perspectives and knowledge of key issues among policymakers. As a result, several resource management policies, such as the National Environmental Management Act (Act No. 107 of 1998) and the National Water Act (Act No. 36 of 1998), have adopted stakeholder consultation as part of their decision-making process prior to issuance of permits [31,32]. From a legislative and policy development perspective, South Africa has made tremendous progress in the adoption of public participation as a way to promote integrated approaches for the management of sectoral challenges, especially in the environmental sector. This is despite concerns that policy and strategy implementation remain untested. The foregoing highlights the importance given to the PA in addressing complex systems within developing communities such as South Africa.

\subsection{Participatory approach in the management of the WECC nexus}

The growing need to emphasise the application of PA within sustainable development is driven by the rapid emergence of new and complex challenges that cannot be addressed from a segmented or sectoral perspective. The mounting challenges associated with water resource management are one example of the various factors that have persuaded the global community to recognize the importance of stakeholder participation, resulting in the endorsement of the IWRM framework. Chief among its key principles, IWRM emphasises the participation of country-specific (local communities) and international actors in the management of water resources [14,33]. Several studies have acknowledged that the application of the PA is vital in management of water resources. This is due to its ability to enable the development of inclusive strategies and institutional frameworks such as Catchment Management Agencies (CMA) within a particular catchment or basin $[34,35,36,37,38]$. The PA has the capacity to bring together key role players such as planners, users, service providers, policymakers, research experts, and local communities to engage, raise concerns and suggestions, and share their knowledge in ways that promote equitable and sustainable usage of water resources within a specific catchment. 
Madzungu (2004) [39] has pointed out that due to the PA's ability to promote inclusive decision-making processes, several countries in SSA have adopted this approach to facilitate collaboration and coordinated development of solutions to their water resource management challenges.

Despite the PA's potential to influence water resource management positively, limiting factors such as political will, lack of skills and technical knowledge, and its financial implications, continue to hamper its effective implementation. According to Biswas (2008) [40] and Suhardiman et al. (2015) [33], the lack of political will to develop inclusive policies based on wide stakeholder consultation has resulted in failure to recognise the importance of the PA in some global communities. Furthermore, Cheru (2002) [41] observed that a lack of effective political leadership has done significant harm and stifled community involvement and grassroots ingenuity in natural resource management. In South Africa, however, PA-aligned strategies have been emphasised to encourage the involvement of all key actors, particularly the marginalised, in governance of natural resources $[19,20]$. For instance, Karar (2008) [42] and DWS (2013) [38] view the successful establishment of institutional frameworks and policies such as CMAs and the National Water Resource Strategy as a representation of efforts that have been made to align policy development within the water resources sector with local communities' needs.

In as much as sustainable water resource management is based on common understanding and a coordinated approach between policymakers and other key stakeholders [33], the advancement could be beneficial to the entire water-linked sectors. In addition, successes around the PA implementation suggests that its implementation could be of importance in assessing nexus configurations such as WECC. The successful implementation of the PA within water resource management further suggests that the approach could also be effective in the assessment of water-linked nexus systems such as WECC. According to Aboelgna et al. (2018) [9] and Hoolohan et al. (2018) [16], applying PA in assessing addressing complex nexus configurations has the potential to promote "nexus thinking" as both approaches are aimed at addressing inextricably linked systems. In addition, recent developments reveal that the PA has proven effective in eliciting understanding of key aspects within the three-legged Water-Energy-Food (WEF) nexus by enabling assessment of key sectors from the perspectives of natural science, social science, and the humanities [43,44]. Thus, Cammerman (2009) [1]and Aboelgna et al. (2018) [9] have observed that a PA that promotes collaboration and a multi-stakeholder approach is an absolute imperative to the management of WECC, which continues to throw up challenges for communities and how they respond to it. The application of the PA in the WECC is further necessitated by the fact that there is a need to bridge the knowledge gap between stakeholders in order to effectively address socio-economic and environmental challenges arising within different communities.

Notwithstanding that the PA seeks to strengthen awareness, broaden understanding, and promote integrated and holistic management of nexus configurations, empirical evidence shows that there are still exclusions and ineffective consultation in its use. These shortcomings are predominantly shown by a lack of policy alignment and the prevailing water, energy, food and climate change sectoral mandates $[45,44,16]$. In some countries such as Argentina and Kenya, for example, lack of emphasis on participatory approaches has resulted in failure to consider geographical locations, community preferences and the exclusion of marginalised societies in the implementation of WECC-efficient projects such as renewable energy water pumping systems [46]. In this instance, critical decisions are likely to be made without full knowledge and understanding of local characteristics or proper stakeholder involvement.

South Africa, which is a climate change hotspot, faces rising demand for water and energy resources. However, one of the critical challenges within these sectors is the dominance of top-down decision-making processes aggravated by the political and socio-eco- 
nomic pressure to address water, energy and climate constrains [44]. Despite the constitutional mandate requiring that key actors, such as government departments, local communities, industry, experts and researchers, are consulted to ensure meaningful, well-informed and effective policy instruments within the water, energy and climate change sectors, application of the PA appears to be lacking. The prevailing lack of coordinated and integrated approaches in the widely touted sectoral policies $[12,13,11,3]$ demonstrates limited application of the PA in planning and implementation processes. These shortcomings suggest a lack of understanding of the interlinkages between the key socio-economic and environmental processes in the WECC nexus. Thus, effective management of WECC and the promotion of awareness, knowledge-sharing and informed policy development in South Africa requires assessment of the nexus through appropriate stakeholder engagement and comprehensive application of the PA.

\section{Materials and methods}

The study reported in paper is based on a qualitative approach whereby in-depth interviews and discussions were conducted with various stakeholders to assess their perceptions on the developments associated with the WECC interaction. The study aimed at understanding the challenges and opportunities emanating from the interaction between the sectors of water, energy and climate change. A non-probable sampling approach, which is mostly used where the likelihood and probability of selecting the participants is not known (see [47]), was used to select the research participants. Both the purposive and snowball sampling techniques were, therefore, critical in the selection of the participants. These two sampling techniques were effective in enabling identification and selection of individuals, groups or organizations that have the knowledge and competencies required to engage on the WECC nexus, thus providing information or data necessary to meet the objectives of the study (See [48,49]. As illustrated in table 1, government departments (i.e. national, provincial and local), the energy and water utilities/agencies non-governmental organizations (NGOs), and academic and research experts as participants in the study were approached and participated in the study. These engagements were corroborated by telephonic discussions held with SSA regional specialist on nexus configurations and sustainable development. Participation of these stakeholders is seen as a positive as key stakeholders of the WECC nexus were represented.

A total of seven (7) focus group discussions and eight (8) one-on-one interviews were held between 30 August 2019 and 10 October 2019. The interviews/discussions were conducted using semi-structured questionnaires covering the following themes: demographic characteristics; assessment of the level of understanding of the WECC; determination of the stakeholder's perspectives on collaboration and coordination; and policy development processes. Each interview/discussion lasted for approximately two hours. The research participants were given pseudonyms to protect their identity. The responses of the participants were captured through an audio recorder. Field notes were transcribed verbatim and kept in their original form. Each transcript was given a code immediately after the interview to ensure clear identification.

In addition to the interviews, the behaviour of the participants during the discussion of the subject matter (See [50, 51]. This technique was applied at a workshop held on 7-8 October 2019. The workshop, which was arranged by the Department of Mineral Resources and Energy (DMRE), discussed progress on energy efficiencies and renewable energy within government infrastructure in South Africa. Forty-five (45) stakeholders, representing different government sectors and water, energy and climate change agencies, attended the workshop. A primary source of data from the workshop is mainly responses to 14 presentations made by attendees. Relevant protocols such as permission to conduct this observation and informing the workshop attendees of this process were obtained prior to collecting the data.

Inductive approach to Grounded Theory was used to develop a theory from the collected data thus allowing systematic analysis of responses from the research participants. The responses were 
grouped based on their significance to the themes. This approach enabled data condensation thus offering simplified, reliable and valid findings (See $[52,53,54])$. This allowed the development of cogent theory of the WECC nexus status in South Africa.

\section{Results and discussions}

This section presents the results of the assessment of several prominent features (i.e. understanding of WECC, policy development, and collaboration) that promote holistic management of the nexus in the context of South Africa. This is vital for enabling the development of a policy framework that drives efficiencies in water and energy supply, while addressing the growing climate change concerns in the country.

\subsection{Profiling the research participants}

Participants responsibly for policy development within the WECC sectors, their agencies, research and academia, as well as NGOs' participated in the study. Validation of participants' experience and knowledge was done by assessing their educational and number or years in the field of study. For instance, Table 1 illustrates that all the participants had a postgraduate qualification while the average experience per sector was above 10 years. In addition, the seniority in their sectors suggests that the participation were from the knowledgeable and authoritative point of view thus allowing for wellinformed perspectives. 
Table 1. Profile of the research participants.

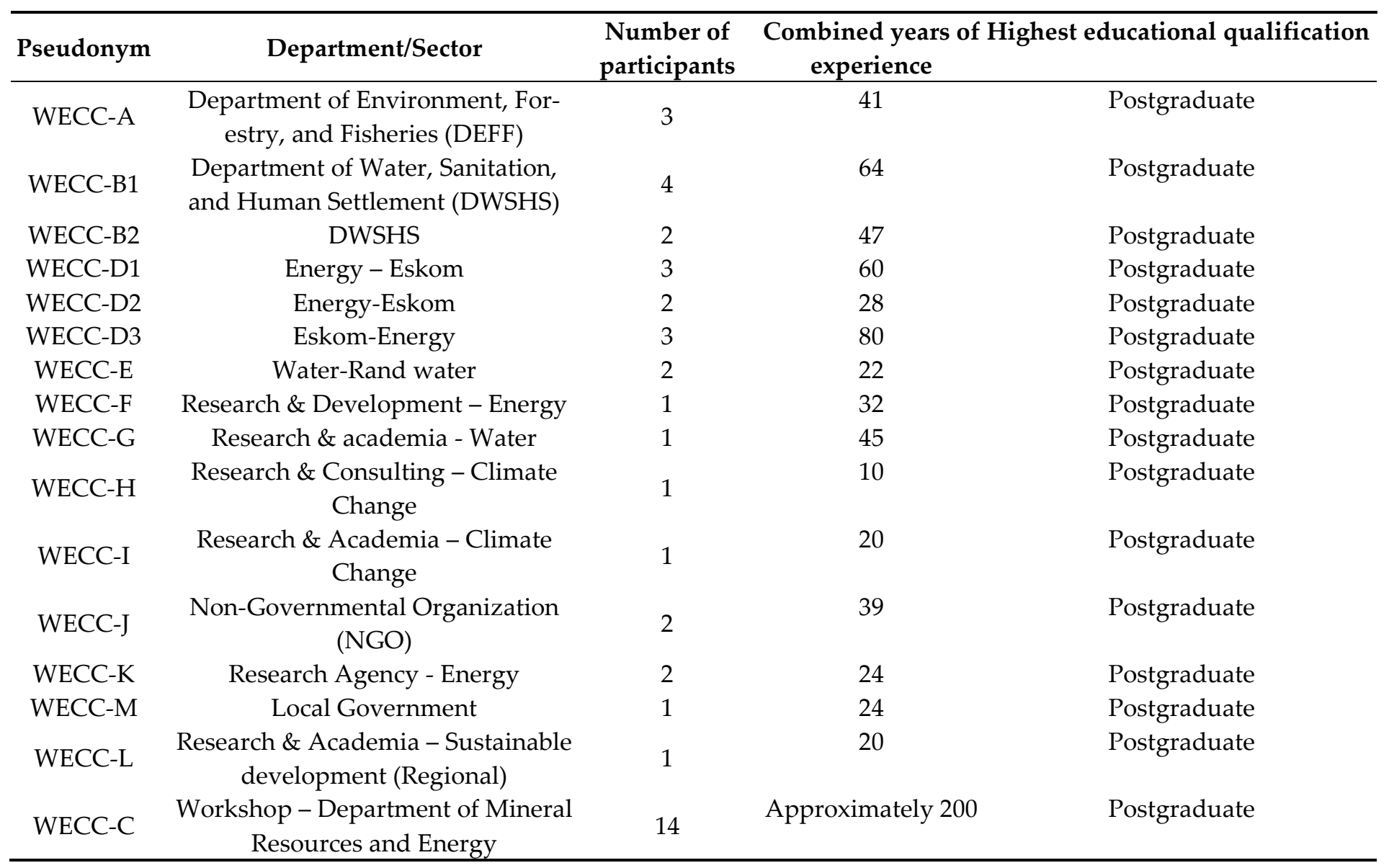




\subsection{Key stakeholders' perceptions of the WECC nexus in South Africa}

This sub-section presents the perceptions of the research participants on the understanding of the WECC nexus in South Africa. This in in support of the assertion of Hoolohan et al. (2018) [16] that understanding and effective management of the nexus configurations can be determined by assessing the perspectives of key stakeholders. The study, therefore, sought to obtain the diverse perceptions of the research participants. This was done in order to determine the extent to which the interlinkages and co-dependency between the nexus components are embraced by key sectors in the country. The assessment was conducted on responses from all research participants (See Table 1). The grouping and analysis of perspectives from these participants are illustrated in Table 2.

Table 2. Perceptions of the research participants on WECC nexus in South Africa.

\begin{tabular}{ccc}
\hline $\begin{array}{c}\text { Coupled WECC interconnec- } \\
\text { tion }\end{array}$ & Number of responses & Percentage (\%) \\
\hline Water-energy-climate change & 18 & 42 \\
Water-energy & 13 & 30 \\
Water-climate change & 9 & 21 \\
Energy-climate change & 3 & 7 \\
Total number of engagements & 43 & 100 \\
\hline
\end{tabular}

Source: Field data (2019)

The responses indicate that $42 \%$ of the research participants have sufficient knowledge of the WECC interconnections in their entirety. This means that these research participants were able to demonstrate how the water, energy, and climate change components interact. For instance, respondent WECC-B $\mathrm{B}_{1}$ illustrated the entirety of the interactions in this nexus by stating that:

"The country's electricity generation system heavily relies on water supply, which its availability is negatively influenced by extreme climate conditions. On the other hand, these climate conditions are exacerbated by the dominant energy production technologies, particularly coal-combustion. In addition, the consequences of climate change also impact the country's energy generation systems" (Personal Communication: Focus group discussion on the 19 September 2019).

Conversely, the majority (i.e., 53\%) of the responses indicate that the perceptions or knowledge of the research participants on the WECC is still sector-based. For instance, $30 \%$ of the participants, who operate mainly within the water and energy sectors, rarely mentioned the linkage or implications of climate change on water and energy resources. These views validate findings of Mabhaudhi et al. (2016) [11] and Mathetsa et al. (2019) [3] that the understanding of the nexus in South Africa is dominated by sectoral boundaries. Participant responses reveal some of the basic reasons behind the prevailing "silo" approach such as policy planning and development within key departments mandated to manage the WECC nexus sectors. This is despite calls for the water, energy and climate change sectors to be managed in a holistic and integrated manner [4,5]. The responses further highlight lack of consensus on how WECC elements are interlinked in South Africa. The observation concur with Head and Cammerman (2010) [2] and Liu et al. (2017) [8] who argued that global communities face the challenge of limited mutual understanding of the WECC interactions, thus limiting their ability to comprehensively manage this nexus. Based on these observations, this study argues that the prevailing sector-based understanding results in inefficiencies and the failure to promote WECC "nexus thinking" in South Africa.

Notwithstanding the lack of mutual understanding of the WECC interactions in South Africa, research participant WECC-L argued that, compared to other SSA countries, 
"South Africa has elaborated significant progress in understanding and analysing the nexus that involves water, energy, food, and climate change" (Personal Communication: a telephonic conversation with Yillia, P.T. on 8 October 2019).

This view is corroborated by several initiatives, among them, technological (i.e. drycooling, emission abatement, renewable energy, and carbon capture) and strategic (i.e. National Water Resource Strategy, National Climate Change Response Strategy, Renewable Energy Independent Power Producers) being developed and implemented in the country. Furthermore, WECC-D 1 , WECC- $\mathrm{D}_{2}$, WECC-D $_{3}$, and WECC-E mentioned these interventions as a way of demonstrating the attention that WECC nexus is receiving at both the operational and planning levels in the country. Further, the discussion efforts such as the WECC-Cs' workshop (see Table 1) also indicate intent on promotion of multistakeholder awareness and understanding of the interactions between these sectors. These developments are relevant in the current landscape as there is a need for the country to identify and develop potential ways to shape and promote a framework for a common understanding of the country's WECC status.

Data gathered from the research participants demonstrates the capacity of the PA to enable analysis of some of the country's prevailing WECC challenges such as limited understanding and fragmented decision-making within the nexus system. While it was assumed that, based on their experience and educational qualifications, the research participants would demonstrate clearly how WECC sectors were interlinked, their responses reflect a dismal understanding of the linkages. This was most evident in the way some of the core elements of the PA (i.e. knowledge-sharing and awareness), were presented and perceived amongst the research participants. There is therefore an opportunity to promote awareness and communication among key WECC sectors as a way to strengthen the understanding of this nexus configuration across society at large. This observation fortifies the argument for "nexus thinking" in the development of mitigation measures and resilient systems to address WECC impacts [9].

\subsection{Collaboration and coordination as a means to implement the WECC nexus in South Africa}

One of the key elements defining this study is the assessment of the research participants' views on the level of coordination and collaboration among various WECC stakeholders in the country. The discussion in this sub-section is informed by Bizikova et al. (2013) [11,44] and Wicaksono (2017) who concur that coordination and collaboration within WECC can be assessed and promoted through the engagement of stakeholders. Table 3 illustrates the views of different research participants on the effectiveness of current coordination and collaboration efforts in respect of the state of the WECC nexus in the country. The views are grouped by organisation/sectors' responses.

Within the water resource management sector, the intensified need for coordination and collaboration is driven by, among others, shared river basins and the dire water status of most international communities [24,14,36]. Similarly, Head and Cammerman (2010) [2] and US DoE (2014) [45] pointed out that coordination and collaboration across all the levels of WECC are important as they avail opportunities for effective resource management and allocation processes such as water transfer schemes, energy exports, and climate change accords. Within WECC, collaboration enables the sharing of resources, data, and information that is relevant for addressing the interdependency between water, energy and climate change. In the Southern African region, and in South Africa particularly, significant collaboration is required among water, energy, and climate change managers to address the WECC challenges and opportunities. 
Table 3: Participants' perspectives on the coordination and collaboration of WECC sectors in South Africa.

\begin{tabular}{ccc}
\hline $\begin{array}{c}\text { Organiza- } \\
\text { tion/Sector }\end{array}$ & $\begin{array}{c}\text { Are the current coordination and collaboration efforts } \\
\text { effective to address WECC challenges? }\end{array}$ & $\begin{array}{c}\text { How can coordination and collabora- } \\
\text { tion be improved? }\end{array}$ \\
\hline DWSHS & $\begin{array}{c}\text { Partially yes, the department liaises with different role } \\
\text { players to develop policy and measures to address wa- } \\
\text { ter challenges and their association with the energy and } \\
\text { climate change sector. }\end{array}$ & $\begin{array}{c}\text { The political will to implement recom- } \\
\text { mendations of scientists. Institutional } \\
\text { mechanisms are similar to those in wa- } \\
\text { ter resource management. E.g. Catch- } \\
\text { ment Management Agencies. }\end{array}$ \\
\hline DMRE & No. WECC dominated by institutional barriers that hin- \\
der collaboration. & $\begin{array}{c}\text { Promote cross-sectoral collaboration. } \\
\text { Enable centralised management sys- } \\
\text { tems such as data coordination and } \\
\text { sharing. }\end{array}$ \\
\hline
\end{tabular}

No. Collaboration is hindered by sectorally approached planning and implementation. For example, coordina-

Energy in- tion can exist from the supply perspective but ineffec- Cross-sectoral coordination, ministerial dustry: tive in the implementation of strategies and policies to and bilateral agreements on water, enEskom increase efficiency. The lack of translation of theory into ergy and climate change. practice creates barriers for coordination across the stakeholders.

Collaborate with water-users to pro-

$\begin{gathered}\text { Local gov- } \\ \text { ernment }\end{gathered}$
No. local government not involved in addressing the
WEC nexus at a national level.

No. Communities entirely excluded from WECC re-

NGOs' lated matters.
Consider the localised dynamics such as water and energy requirements. Strengthen the local level interactions. Enable community participation in critical decision-making processes. Consideration of community requirements. Establishment of government-industrycommunity committees that are independently managed.

Combined research activities within WECC to close the knowledge gap between local communities, industries, researchers and policymakers

Source: Field survey (2019)

The majority of the research participants were of the view that the coordination and collaboration efforts are insufficient to deal with the existing WECC challenges threatening the country's developmental endevours. One significant example raised is the lack of collaboration and coordination between key governmental departments in the water, energy and climate change sectors, particularly in the planning and development of policy. For instance, when asked about collaboration amongst government stakeholders, WECC-A explicitly responded that:

"There is a lack of collaboration amongst the policymakers and different stakeholders such as local communities particularly in the inclusion of emerging science such as climate change in 
the nexus". - (Personal communication: focus group discussion on the 20 September 2019)

Given the consequences of ineffectively managed systems, responses such as the one given above highlight the importance of enforcing collaboration amongst key ministries of WECC sectors. In Kenya, for example, the lack of collaboration and cooperation among players at key levels of institutions resulted in conflicting and duplicate plans in the country's water, energy, and food supply systems [9]. This corroborates the assertion by Mathetsa et al. (2019) [3] that key sectors and organisations that fail to collaborate at both the operational and policy development levels aggravate sectoral mandates and inefficiencies in WECC management. Another key challenge raised by research participants is the lack of collaboration with other sectors, such as industries and communities, to address WECC challenges. This is despite the crucial role communities play in providing necessary information to deal with WECC issues and the fact that, being at the end of the food chain, they are significantly exposed to impacts of the nexus (See $[45,9]$. In addition, respondents raised concern with the competition between institutions which exacerbates the knowledge gap between researchers, government agencies and communities. This is in line with the argument by Conway et al. (2015) [56] that there is a knowledge gap between both researchers and non-researchers which results in exclusions during decision-making processes and hinders the identification and incorporation of all levels of society in the effective management of WECC.

These observations seem to suggest that both vertical (governmental) and horizontal (all sectors) coordination and collaboration have not been optimised in South Africa. This is worsened by institutional barriers within the WECC sectors perpetuated by the complex connection and competition between these three elements [9]. This is unlike the situation in the water resources management sector wherein Karar (2008) [42], Pollard and Du Toit (2008) [36], and DWS (2013) [38] concur that the establishment of institutional arrangements such as CMAs has enabled the promotion of collaboration and coordination. Aboelgna et al., (2018) [9] is of the view that changes in institutional structures and the procedural and communication instruments are necessary for promoting coordination and collaboration. Participants suggests that implementation of platforms such as co-planning and policy development, inter-ministerial task teams, cross-sectoral coordination, bilateral agreements, joint committees across the technical, research and academia, ministerial and local levels, and the enablement of financial structures where WECC components are lacking could be key in fostering collaborations. Taking this into consideration, implementation of coordinated and collaborative strategies has the potential to trigger effective WECC management, and that enabling tools such as funding, data, information, modelling, technology, policy analysis, and political to be unveiled to mitigate the implications of the WECC on all sub-sectors of the economy.

\subsection{Perceptions of research participants on policy development in WECC sectors in South Africa.}

Policy is one of the key drivers of efficiency in resource consumption. The growing demand for communities to address water and energy efficiencies while curbing climate change impacts suggests that robust policies are required. However, Head and Cammerman (2010) [2], US-DoE (2014) [45] and Carpenter (2015) [57] have argued that the complexity and fragmentation of water, energy and climate change sectors require deviations in the decision-making landscape of WECC, with policy integration paramount. This sub-section assesses the views of research participants on the current policy decision-making landscape in South Africa (see Table 4).

Table 4: Perceptions of research participants on policy development in South Africa 


\begin{tabular}{cccc}
\hline $\begin{array}{c}\text { WECC policy de- } \\
\text { velopment }\end{array}$ & No of participants & $\begin{array}{c}\text { Number of re- } \\
\text { sponses }\end{array}$ & Percentage (\%) \\
\hline Policy Integration & 43 & 43 & 100 \\
Fully & & 6 & 14 \\
Moderate & 14 & 33 \\
$\quad$ Poor & 43 & 23 & 53 \\
Consultation dur- & & 43 & 100 \\
ing policy Develop- & & & \\
ment & & 7 & 16 \\
Fully & 11 & 26 \\
Moderate & 25 & 58 \\
poor & & & \\
\hline
\end{tabular}

Source: Field survey (2019)

The responses were divided into two sub-themes, namely, the views of participants on WECC sectors integration, and consultation of key stakeholders during policy development. Most research participants (i.e. 53\%) were of the view that the current policies across the water, energy and climate change sectors were developed in isolation. For instance, WECC-A said,

"despite the emergence of climate change as an overarching component in the energy and water supply, the development of the climate change, water, and energy policies are still not aligned" (Personal communication: focus group discussion on the 20 September 2019).

This fragmented policy development, which has also been observed by several other studies in the country $[56,11,3]$, points to the existence of sectoral mandates within different government departments. This is a common challenge across the globe [6,9]. This fragmentation also raises concerns related to policy implementation, with WECC-D1, WECC- $\mathrm{D}_{2}$, WECC- $\mathrm{D}_{3}$, and WECC-C highlighting conflicting compliance expectations from different policymakers. In addition, responses from the participants confirm the existence of sectorally mandated policies that are limited to certain coupled interactions. For instance, WECC-B1 pointed out that there is a development of "key departmental policies such as Sustainable Hydropower Generation Policy which is responsible to ensure that there is sufficient water available for the hydropower generation technology" (Personal communication: focus group discussion on the 19th September 2019).

Other research participants, however, indicated that they were not aware of such policy, thus suggesting a "silo" approach, and lack of communication and awareness in the development of these critical policies. However, several research participants (i.e. $33 \%$ ) have observed an improvement in the development of policies, with consideration given to each of the WECC elements. For instance, WECC-G and WECC-L stated that the development of the energy policy, Integrated Resource Plan (IRP) 2010-2013, took into consideration water scarcity and climate change impacts. This is another landmark example demonstrating the progress made by South Africa in drafting policies that drive alignment of WECC nexus elements.

One of the key drivers of fragmented policy development globally is the lack of consultation amongst broader stakeholders in the WECC nexus (Cammerman, 2009; Head and Cammerman, 2010). In this study, 58\% of the research participants were of the view that the current consultation approach among key WECC stakeholders is poor and unsatisfactory. This lack of consultation is, according to Chambers (1994) [17] and GWP (2000) [14], aggravated by the top-down decision-making approach practiced in most 
societies. Despite suggestions by Head and Cammerman (2010) [2] and Mohtar (2017) [57] that complex problems such as WECC require a multiscale approach, particularly at the policy making level, this study found that the dismal policy integration efforts in the country are aggravated by inefficiency in stakeholder consultation processes. This observation strongly suggests that there is a need for change in the decision making and policy development landscape based on broader and inclusive stakeholder engagement with the intent to increase efficiencies in the management of the WECC nexus in South Africa. Until such change is realised, the WECC nexus will continue to hamper socioeconomic development as well as environmental wellbeing in the country. This assertion is made based on the current and projected impacts of climate change in South Africa. There is, therefore, urgent need for integrated policies and strategies that have a bearing on the challenges associated with the WECC nexus the country.

\section{Conclusions}

The study applied a PA to assess the views of multiple stakeholders on WECC and the effectiveness of current tools and approaches such as policy development and collaboration in the management of this nexus in South Africa. Based on the perceptions of the research participants, the study made three key findings. First, it is evident that there is a dearth of understanding and acknowledgement of WECC existence in South Africa. This is validated by the lesser ratio of research participants demonstrating their full understanding of coupled WECC interactions. This limited understanding is regardless of the notable level of education and experience that the research participants had in the respective sectors. Secondly, despite the growing need to address the WECC challenges, it was established that a lack of coordination and collaboration, both vertically (between decision-makers such as government departments) and horizontally (between stakeholders such as government departments, industry, and local communities) still exists. It is however noted that the need for collaboration is imperative, as noted by many research participants, given the efforts made to discuss and raise concern on lack thereof. Thirdly, sector-driven policy planning and development are still dominant in South Africa. It was, however, observed that there are efforts to integrate the development of policies in recognition of the interdependence between sectors. Initiatives and engagement such as ministerial committees, donor-funding, and research teams have been observed to promote collaboration and an integrated approach.

One of the most significant contributions of this study is identification of the important role that the PA plays in promoting a holistic and coordinated management of WECC in South Africa. The data collection techniques applied in this study showed that this approach is pivotal in assessing WECC, and in enabling the country to understand the risks and opportunities that the WECC nexus presents for all sub-sectors of the economy. It is, therefore, suggested that South Africa look into the prospects of developing an institutional and policy framework that will promote the implementation of participatory approaches within WECC nexus systems. Part of the requirements in this process will be investment in skills development for actors within the sectors that can manage the impacts of this WECC nexus. Lastly, while the study confined itself to the stakeholders perceptions, the country must establish a data management system from which all actors within the WECC system can draw information to enable holistic alignment of their policies and strategies.

Author Contributions: S.M. and M.S. did the conceptualization; S.M. was responsible for methodology, formal analysis, investigation, data curation and writing - original draft preparation. M.S. and I.R. did the review and editing. All authors have read and agreed to the published version of the manuscript." 
Funding: The authors are grateful for the following funding bodies: Eskom - Research, Testing and Development (grant number N.RA.60008.R.02.009), and the University of the Witwatersrand.

Acknowledgments: The authors would like to thank Eskom, The Department of Water, Sanitation, and Human Settlement, The Department of Environment, Forestry and Fisheries, and the Department of Mineral Resources and Energy Eskom, for their assistance in the data collection.

Conflicts of Interest: The authors declare no conflict of interest. The funders had no role in the design of the study; in the collection, analyses, or interpretation of data; in the writing of the manuscript, or in the decision to publish the results.

\section{References}

1. Cammerman, N. Integrated water resource management and the water, energy, climate change nexus: a discussion report. Unpublished MSc Thesis. University of Queensland, Australia, 2009.

2. Head, B. and Cammerman, N. The Water-Energy Nexus, A policy Challenge for Knowledge and Policy. Technical Report No. 39. Urban Water Security Research Alliance, 2010. Available online: http://www.urbanwateralliance.org.au/publications/UWSRA-tr39.pdf (accessed on 06 April 2019).

3. Mathetsa, S.M., Simatele, M.D., Rampedi, I.T. Gericke, G. Perspectives on integrated water resource management and its relevance in understanding the water-energy-climate change nexus in South Africa. Journal of Energy in Southern Africa, 2019, 30 (3). pp 11-21. DOI: http://dx.doi.org/10.17159/2413-3051/2019/v30i3a5654.

4. Mukheibir, P. Water Resources Management Strategies for adaptation to climate-induced impacts in South Africa. Water Resources Management, 2008. Vol. 22, pp. 1259-1276. DOI: https://doi.org/10.1007/s11269-007-9224-6.

5. Cullis, J.D.S; Walker, N.J., Ahjum, F. Rodrigues, D.J. Modelling the water energy nexus: should variability in water supply impact on decision making for future energy supply options?. Int. Association of Hydrological Sciences, 2018. Vol. 376, pp 3-8. DOI: https://doi.org/10.5194/piahs-376-3-2018.

6. Brazilian, M., Rogner, H., Howells, M., Hermann, S., Douglas, A., Gielen, D., Steduto, P., Mueller, A., Komor, P., Tol, S. J. R. Yumkella, K. K. Considering the energy, water and food nexus: Towards an integrated modelling approach. Energy Policy, 2011, 39. pp. 7896-7906.DOI https://doi.org/10.1016/j.enpol.2011.09.039.

7. Hussey, K. Pittock, J. The energy-water nexus: Managing the links between energy and water for sustainable future. Ecology and Society, 2012, 17(1). pp. 31-39. DOI: https://doi.org/10.5751/es-04641-170131.

8. Liu, J., Yang, H., Cudennec, C., Gain, A.K., Hoff, H., Lawford, R., Qi, J., Strasser, L. de, Yillia, P.T., Zheng, C. Challenges in operationalizing the water-energy-food nexus. Hydrol. Sci. J., 2017, 62, pp. 1714-1720. DOI: $\underline{10.1080 / 02626667.2017 .1353695 . ~}$

9. Aboelgna, H.T, Khalifa, M., McNamara, I., Ribbe, L. Sycz, J. The water-Energy-Food security nexus: a review of nexus literature and ongoing nexus initiatives for policymakers. Nexus Regional Dialogue Programme, 2018. Available online:

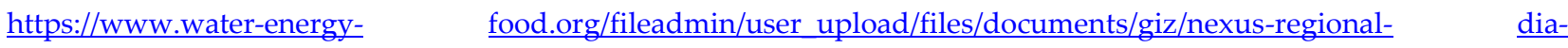
logues/WEF_Nexus_Literature_Review.pdf (accessed on 22 June 2019). 
10. Prasad, G., Boulle, M., Boyd, A., Rahlao, S., Wlokas, H. and Yaholnitsky, I.. Energy, water and climate change in Southern Africa. What are the issues that need further investment and research? Energy Research Centre, 2012. University of Cape Town, Cape Town, South Africa. DOI: http://hdl.handle.net/11427/16906.

11. Mabhaudhi, T., Mpandeli, S., Madhlopa, A., Modi, A.T., Backeberg, G. and Nhamo, L. (). Southern Africa's Water-Energy Nexus: Towards Regional Integration and Development. Water, 2016, 8 (6). pp 1-21. DOI: https://doi.org/10.3390/w8060235.

12. Nhamo, L., Ndlela, B., Nhemachena, C., Mabhaudhi, T., Mpandeli, S. and Matchaya, G. (2018). The water-energy-food nexus: Climate risks and opportunities in Southern Africa. Water, 2018, 10 (5). Pp. 567-584. DOI: https://doi.org/10.3390/w10050567.

13. Gobin, A., Sparks, D., Okedi, J., Armitage, N. Ahjum, F. (2019). Assessing the energy and carbon footprints of exploiting and treating brackish groundwater in Cape Town. Water $S A, 2019,45$ (1), pp. 63 - 74. DOI: 10.4314/wsa.v45i1.08

14. Global Water Partnership. Integrated Water Resources Management. Report by Technical Advisory Committee. TAC background papers no. 4, 2000. Stockholm, Sweden.

15. Flammini, A., Puri, M., Pluschke, L., Dubois, O. Walking the Nexus Talk: Assessing the Water-Energy-Food Nexus in the Context of the Sustainable Energy for All Initiative; Climate, Energy and Tenure Division (NRC), Food and Agriculture Organization of the United Nations (FAO), 2014, Rome, Italy. Available Online: http://www.fao.org/3/ai3959e.pdf (accessed on 16 May 2019).

16. Hoolohan, C., Larkin, A., McLachlan, C. Engaging stakeholders in research to address water-energy-food (WEF) nexus challenges. Sustain Sci. 2018, 13, 1415-1426 (2018). DOI: https://doi.org/10.1007/s11625-018-0552-7.

17. Chambers, R. Participatory rural appraisal (PRA): Analysis of experience. World Development., United Kingdom, 1994.

18. Babooa S.K. Public participation in the making and implementation of policy in Mauritius with reference to Port Louis' local government. Unpublished Doctor of administration Thesis. University of South Africa, 2008.

19. Nyathi, L. (2008). Public Participation: What has the Constitutional Court given the public?. African Journals Online, 2008, 12 (2), pp. 102-110. DOI: $\underline{10.4314 / 1 d d . v 12 i 2.52896}$

20. Legislative Sector Support. Public Participation Framework for the South African Legislative Sector, 2013. Available online: http://sals.gov.za/docs/pubs/ppf.pdf (accessed on 18 November 2019).

21. Dungumaro, E.W. Madulu, N. F. Public participation in integrated water resource management: the case of Tanzania. Physics and Chemistry of the Earth, 2003, 28, pp. 1009-1014. DOI: https://doi.org/10.1016/j.pce.2003.08.042.

22. Alam, A. Ihsan, S. Role of Participatory Rural Appraisal in Community Development (A Case Study of Barani Area Development Project in Agriculture, Live Stock and Forestry Development in Kohat). International Journal of Academic Research in Business and Social Sciences, 2012, 2 (8).

23. Barreteau, O., Bots, P., Daniell, K., Etienne, M., Perez, P. Barnaud, C., Bazile, D., Becu, N., Castella, J.C., Dare, W. Trebuil, G. "Participatory approaches" In: Simulating Social Complexity, Springer. Manchester. United Kingdom, 2013. 
24. Barbosa, M.C., Mushtaq, S. Alam, K. Integrated water resources management: Are river basin committees in Brazil enabling effective stakeholder interaction?. Environmental Science \& Policy, 2017, 76 (C), pp. 1-11. DOI: https://doi.org/10.1016/j.envsci.2017.06.002.

25. Kubanza, N.S. Simatele M.D. Solid waste management and environmental injustice in poor communities in Kinshasa: A cultural theory and systems approach. Journal of Environmental Management and Sustainable Development, 2019, 8, (1), ISSN 2164-7682.

26. Denby, K.; Movik, S.; Mehta, L. van Koppen, B. The 'trickle down' of IWRM: A case study of local-level realities in the Inkomati Water Management Area, South Africa. Water Alternatives, 2016, 9(3), pp. 473-492.

27. Mathekga, R. Buccus, I. The challenge of local government structures in South Africa: securing community participation. Critical Dialogue Public Participation Rev, 2006. 2 (1), pp. 11-17. Available online: http://citeseerx.ist.psu.edu/view-

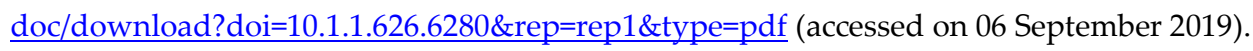

28. Prinsloo, M. (2008). Community-based participatory research: A case study from South Africa, 2008. Available Online: http://www.in-fusion.co.za/resources/article_community_based_research.pdf (accessed on 04 October 2019).

29. Fatch, J.J. Local participation in transboundary water resources management: The case of Limpopo Basin, Zimbabwe. Unpublished MSc Thesis. University of Zimbabwe, 2009.

30. The Constitution of the Republic of South Africa. 1995. South Africa.

31. Department of Environmental Affairs. National Environmental Management Act, 107 of 1998 . The Republic of South Africa, 1998.

32. Department of Water and Sanitation [DWS]. National Water Act, 36 of 1998. The Republic of South Africa, 1998.

33. Suhardiman, D. Clement, F. Bharati, L. Integrated water resources management in Nepal: key stakeholders' perceptions and lessons learned. International Journal of Water Resources Development, 2015, 31 (2), DOI: https://doi.org/10.1080/07900627.2015.1020999.

34. Rahaman, M.M., Varis, O., Kajandereu, T. Water Framework Directive vs. Integrated Water Resources Management: The Seven Mismatches. Water Resources Development, 2004, 20 (4), pp. 565-575. DOI: https://doi.org/10.1080/07900620412331319199.

35. Burt, J.C., Du Toit, D.R., Neves, D. Learning about participation in IWRM: A South African review, Water Research Commission, Pretoria, South Africa, 2005.

36. Pollard, S., Du Toit, D. Integrated water resource management in complex systems: How the catchment management strategies seek to achieve sustainability and equity in water resources in South Africa. Water SA, 2008, 34 (6), pp. 671680. DOI: https://doi.org/10.4314/wsa.v34i6.183668. 
37. Jingling, L., Yun, L., Liya, S., Zhiguo, A., Baoqiang, Z. Public participation in water resources management of Haihe river basin, China: the analysis and evaluation of status quo. Procedia Environmental Sciences, 2010, 2, pp. 1750-1758. DOI: https://doi.org/10.1016/j.proenv.2010.10.187.

38. DWS. National Water Resource Strategy: water for equitable and sustainable future. Government printers. Pretoria, South Africa, 2013.

39. Madzungu E. Water For All: Improving Water Resource Governance in Southern Africa. gatekeeper series no.113. International Institute for Environment and Development, Natural Resources Group and Sustainable Agriculture and Rural Livelihoods Programme, 2004. Available Online: https://dlc.dlib.indiana.edu/dlc/bitstream/handle/10535/6097/113.pdf?sequence=1\&isAllowed=y (accessed on 22 October 2019].

40. Biswas, A. K. Integrated Water Resources Management: Is it working? International Journal of Water Resource Development, 2008, 24(1), pp. 5-22. DOI: https://doi.org/10.1080/07900620701871718.

41. Cheru, F. African Renaissance: Roadmap to the challenge of globarisation. ZED Books, London, 2002.

42. Karar, E. Integrated water resource management (IWRM): Lessons from implementation in developing countries: Foreword to the IWRM conference special edition. Water SA, 2008, 34(6). Pp. 661-664. https://doi.org/10.4314/wsa.v34i6.183666.

43. Endo, A., Burnett, K., Orencio, P.M., Kumazawa, T., Wada, C.A., Ishii, A., Tsurita, I., Taniguchi, M. Methods of the waterenergy-food nexus. Water (Switzerland), 2015, 7, pp. 5806-5830. DOI: 10.3390/w7105806.

44. Wicaksono, A., Jeong, G., Kang, D. Water, energy, and food nexus: review of global implementation and simulation

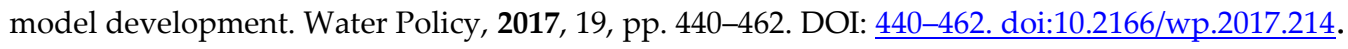

45. United States Department of Energy (US DoE). The water-energy nexus: Challenges and opportunities. Report for the US DoE, June 2014.

46. Platonova, I. Leone, L. The energy-water nexus in the context of climate change in developing countries: Experiences from Latin America, East and Southern Africa. In: Synthesis Report for Climate Change and Water Program, Ottawa, Canada. 7 November 2012.

47. van Zyl, L. E. Research Methodology for Economic and Management Sciences. Cape Town, South Africa. Pearson Education Limited, 2014.

48. Tongco, M.D.C. Purposive Sampling as a Tool for Informant Selection. Ethnobotany Research and Applications, 2007, 5. pp. 147-158. DOI: $\underline{10.17348 / \text { era.5.0.147-158. }}$

49. Kirchherr, J., Charles, K. Enhancing the sample diversity of snowball samples: Recommendations from a research project on anti-dam movements in Southeast Asia. PLoS ONE, 2018, 13 (8), e0201710. DOI: https://doi.org/10.1371/journal.pone.0201710.

50. Dawson, C. Practical Research Methods: A User-friendly Guide to Mastering Research Techniques and Projects. Oxford: How To Books Ltd, 2002. 
51. Kawlich, B. Participant observation as a data collection method. Forum Qualitative Sozialforschung / Forum: Qualitative Social Research 2005, 6(2), Art. 43, available online: http://nbn- resolving.de/urn:nbn:de:0114-fqs0502430 (accessed on 08 October 2019).

52. Mills, J., Bonner, A., Francis, K. The development of constructivist grounded theory. International Journal of Qualitative Methods 2006, 5(1), Article 3. Available online: http://www.ualberta.ca/ iiqm/backissues/5 1/pdf/mills.pdf (accessed on 14 October 2019).

53. Thomas, D.R. A general inductive approach for analyzing qualitative evaluation data. American Journal of Evaluation 2006, 27, 2, pp. 237-246. DOI: https://doi.org/10.1177/1098214005283748.

54. Charmaz, K.. Constructive grounded theory: A practical guide through qualitative analysis. SAGE Publications, London 2013.

55. Bizikova, L., Roy, D., Swanson, D., Venema, H.D., Mccandless, M. The Water-Energy-Food Security Nexus: Towards a practical planning and decision-support framework for landscape investment and risk management. International Institute of Sustainable Development Report. 2013. Available online: http://www.cilt.uct.ac.za/sites/default/files/image_tool/images/91/Bizikova\%20et\%20al.\%20wef_nexus_2013\%20IISD.pdf. (accessed on 22 February 2019).

56. Conway, D.; van Garderen, E. A.; Deryng, D.; Dorling, S.; Krueger, T.; Landman, W.; Lankford, B.; Lebek, K. Osborn, T.; Ringler, C.; Thurlow, J.; Zhu, T.; Dalin, C.; van Garderen, A. Climate and southern Africa's water-energy- food nexus Climate and southern Africa's water-energy-food nexus. National Climate Change, 2015, 5, pp. 837-846. DOI: https://doi.org/10.1038/nclimate2735.

57. Carpenter, A. M. Water availability and policies for the coal power sector. IEA Clean Coal Centre, Report No.ccc/256. United Kingdom, 2015.

58. Mohtar R.B. A call for a new business model valuing water use and production: the Water, Energy and Food Nexus holistic system approach. Water International, 2017, 42 (6), pp. 773-776. DOI: http://doi.org/10.1080/02508060.2017.1353238. 